\title{
Review of "Seven Quartets of Becoming: A Transformative Yoga Philosophy Based on the Diaries of Sri Aurobindo" by Banerji, D.
}

\author{
Jon L Dorbolo
}

\section{Correspondence: Jon.Dorbolo@oregonstate.edu Department of Philosophy, Oregon State University, Corvallis 97331, USA}

\author{
Book details \\ Banerji, D. \\ Seven Quartets of Becoming: A Transformative Yoga Philosophy Based on the Diaries \\ of Sri Aurobindo \\ Los Angeles, CA: Nalanda International, 2012, Pages: 441, ISBN: 978-8124606260
}

Keywords: Aurobindo; Yoga; Integral; Transformation; Diaries; Perfection; Consciousness

\section{Main text}

A thinker's journal maps the domain of an examined life. A writer's journal is at once more private and more revealing than their public writing since the journal is selfdirected thought. Scholarship on a writer is impelled by access to their self-reflections such as with the personal journals of Kierkegaard and Emerson. Sri Aurobindo (18721950) kept detailed journals from 1909 to 1927. Those journals, collectively titled Record of Yoga, have only recently been published in book form in 2001 ${ }^{\mathrm{a}}$. With Sri Aurobindo's personal journals available as a whole the door is open to new scholarship on this revolutionary-poet-mystic-saint and his philosophical psychology of integral yoga.

In Seven Quartets of Becoming: A Transformative Yoga Psychology Based on the Diaries of Sri Aurobindo, Debashish Banerji provides the first sustained analysis of the Record of Yoga with an emphasis on Sri Aurobindo's system of yogic integral transformation, the seven chatusthayas (quartets or quaternaties). This review is focused on ways that Banerji's analysis may be fruitfully employed; biographical, textual, scholarly, psychological, philosophical, and spiritual.

\section{Biographical}

Sri Aurobindo's life story is fascinating as so richly related by Peter Hees in his biography The Lives of Sri Aurobindo ${ }^{\mathrm{b}}$. Hees devotes part of a chapter to Record of Yoga and the seven chatusthayas. Where Hees describes the system in brief, Banerji builds a whole study. His exegesis adds much to understanding Sri Aurobindo as a person by situating the seer's words in the context of action and experiment. Viewing Record of Yoga as largely an experimental journal which records the results of empirical tests helps in interpreting the cryptic character of its entries. Sri Aurobindo kept his 
journals as a way of measuring progress in his yogic practice. He was not only expounding a theory of individual transformation but was earnestly seeking it. Much of what he tells us about the possibilities of consciousness are related from personal experience; the basis of his mysticism.

\section{Textual}

Banerji traces connections between the system of seven chatusthayas and Sri Aurobindo's major works particularly Synthesis of Yoga ${ }^{\mathrm{c}}$, The Supramental Manifestation ${ }^{\mathrm{d}}$, and The Mother ${ }^{\mathrm{e}}$, Early in Record of Yoga there occurs an "Outline of the Seven Chatusthayas". As interpreted by Banerji these are (1) the elements of perfection, (2) perfection of being, (3) perfection of action, (4) perfection of peace, (5) perfection of power, (6) perfection of knowledge, and (7) perfection of body. These correspond to the seven constituents of consciousness found in the Vedas and Upanishads. These textual connections are significant because Sri Aurobindo's writing is pervaded by associations to the scriptures. A depth interpretation of his writing cannot forego those co-textual relations. The seven chatusthayas offer an architectural blueprint of his life's work and Banerji's analysis acts as a reading of the blueprint with overt attention to the unity of Sri Aurobindo's thought. Banerji's focus on the seven chatusthayas as key to integral yoga leaves less attention to the content of Record of Yoga which totals more than 1,500 pages. There remains work to be done to interpret this body of writing in its own right.

\section{Scholarly}

Banerji's analysis lays a groundwork for new scholarly approaches to Sri Aurobindo's integral yoga which may lead to increasing significance of it within the traditions of both Indian and Western thought. A fresh direction is established by juxtaposition of Sri Aurobindo with postmodern philosophers including Giles Deleuze (1925-1995), Felix Guattari (1930-1992), Michel Foucault (1926-1984), and Luce Irigaray (1930). Banerji makes a compelling case in particular for comparative study of Sri Aurobindo and Deleuze. While raising these juxtapositions is a significant contribution to scholarship, Banerji's use of postmodern philosophers as interlocutors throughout the text is less successful in terms of explanatory power. Often the French postmodern writers are less accessible than Sri Aurobindo who in his major works so successfully achieved academic clarity, at least for Anglo-American readers. For those not versed in continental postmodern philosophy such comparisons do little for elucidation.

\section{Psychological}

Sri Aurobindo regarded his integral yoga as a practical psychology. Seen through the system of the seven chatusthayas it is a sophisticated analysis of the elements and processes of human consciousness. Sri Aurobindo did not identify unity with simplicity. His system of the enumerations and relations in consciousness is complex. Working through that complexity to find a system is the primary success of Seven Quartets of Becoming. Each of the seven chatusthayas (quartets or quaternaries) consists of four goals, the achievement of which constitutes a particular perfection. The goals are aspects of personality and individual consciousness that may be transformed towards a higher state of divinity. The goals are often interdependent though seldom merely a 
linear progression. The chatusthayas act on one another and the goals of one chatusthaya may operate across the domains of others, creating multivariate layers of complexity. Banerji addresses all twenty-eight of these goals and how for each chatusthaya they operate together to form a coherent concept of perfection.

\section{Philosophical}

While explaining the goals of the chatusthayas Banerji consistently relates them to key philosophical concepts and issues in Indian and Western thought. Most significant is the double principle, liberation (mukti) and enjoyment (bhukti), by which Sri Aurobindo establishes a root schema for the concepts of his system. Many spiritual systems, certainly in the Indian traditions, seek liberation from conditioning, desire, and the vicissitudes of existence. Often these movements adopt asceticism or discounting the physical in which enjoyment is to be found. Sri Aurobindo insists that both liberation and enjoyment must be attained in the perfection of human capabilities in order to form a unified consciousness. A concentration on liberation to the exclusion of enjoyment, or vice versa, is to fasten to one side of the duality which is the root source of the disintegration of consciousness.

This duality may recall Isaiah Berlin's distinction between freedom from and freedom to in which freedom from coercion has no practical value without freedom to (wards) one's potential; what value has freedom to those who cannot exercise it? ${ }^{\mathrm{f}}$ Banerji places right emphasis on the role that finding unity in duality plays in Sri Aurobindo's system;

"This leads us to the goal of integral transformation, which intends to arrive at a perfection of the conditions and experience of becoming based on perfection of being. The perfection of becoming implies a perfect enjoyment (bhukti) while the perfection of being implies the intrinsic freedom of divine being (mukti). An integral transformation must, thus include both liberation and enjoyment (mukti and bhukti). And we see that these two are related causally as per the relation of being and becoming - that is, a perfect mukti is the condition for a perfect bhukti". g

So it is that liberation and enjoyment form a central structure within the seven chatusthayas. Half of each quartet (two goals) is liberatory (freedom from) and the other half is enjoyment oriented (freedom to). This dual principle is just one, though perhaps the most fundamental, of the structural properties of Sri Aurobindo's system of integral yoga. The strength of Banerji's analysis is in bringing those elements, relations, and directions to the fore.

\section{Spiritual}

A key feature of Sri Aurobindo's work is his notion that humanity is a stage on the way to a higher, and no longer human, being. One of Banerji's stated objectives for Seven Quartets of Becoming is to facilitate understanding of the processes and goals of integral transformation. This is a high aim because he seeks exegesis of a spiritual thinker whose quest is to found a practical psychology which describes a path leading beyond the human condition to a unified consciousness which transforms its world. If Sri Aurobindo's 
quest is possible it is fair to ask whether Banerji's objective is viable. Is it possible for human thought to apprehend a state which exceeds human limits? If so, we would need to circumscribe within the limit that which exceeds it. If not, then to whom is the explanation addressed? For the premise of integral yoga is that we start within the limit. We are the humans which the integral becoming will transform beyond.

A theme that resonates throughout Sri Aurobindo's works is that we exceed our own limits by an aspiration that guides the will. Forming a genuine higher conception of oneself carries us upward to meet it. Banerji's exegesis facilitates Sri Aurobindo's practical objective of awakening the reader's aspiration towards integral transformation. Integral becoming germinates in aspiration, as Banerji explains;

"It is something that the aspirant is seeded with. Once the resolution is made, there burns something within the heart which must be constant, adhering to the goals of the seven quartets. This is the will to progress in integral becoming".

We can only act upon that which we believe possible. Expanding our sense of the possible is essential to Sri Aurobindo's integral yoga. Banerji's exegesis is effective in making those possibilities more accessible.

Seven Quartets of Becoming is a readable and insightful approach to some of the problematic constants of philosophy both East and West. The book manages to explain and use Sanskrit and English technical terminology without losing the flow of ideas. Banerji is Dean of Academic Affairs at the University of Philosophical Research. He developed Seven Quartets of Becoming while teaching courses on Indian thought and Sri Aurobindo. I recommend his lectures from the course The Yoga of Integral Transformation as a valuable supplement to his book. ${ }^{i}$

\section{Endnotes}

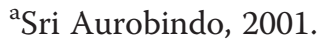

${ }^{\mathrm{b}}$ Hees, P. 2008.

${ }^{\mathrm{c}}$ Sri Aurobindo, 1990 (2).

${ }^{\mathrm{d}}$ Sri Aurobindo. 1989.

${ }^{\text {e }}$ Sri Auroboindo. 1990 (1).

f Berlin, I. 1969, Ch. 3.

gBanerji, D., 2012, P.7.

${ }^{\mathrm{h}}$ Ibid., p.332.

${ }^{\mathrm{i}}$ University of Philosophical Research. http://www.uprs.edu.

\section{Competing interests}

The review author has no financial competing interests. The review author completed three graduate courses taught by the book author. The review author is developing a Critical Thinking course for the University of Philosophical Research (UPR) at which the book author is the Dean of Instruction. This fact is not related to the content and topic of the submitted book review, but there it is. The review author has no other competing interests; political, personal, religious, ideological, academic, intellectual, or commercial. 
Received: 20 December 2014 Accepted: 26 January 2015

Published online: 25 March 2015

\section{References}

Aurobindo, Sri. 1989. The Supramental Manifestation \& Other Writings. Twin Lakes, Wisconsin: Lotus Press.

Auroboindo, Sri. 1990. The Mother. Twin Lakes, Wisconsin: Lotus Press.

Aurobindo, Sri. 1990. Synthesis of Yoga. Twin Lakes, Wisconsin: Lotus Press.

Aurobindo, Sri. 2001. Record of Yoga I \& II. Pondicherry, India: Sri Aurobindo Ashram Publication Department.

Banerji, D. 2012. Seven Quartets of Becoming: A Transformative Yoga Philosophy Based on the Diaries of Sri Aurobindo. Los Angeles, CA: Nalanda International.

Berlin, I. 1969. Four Essays on Liberty. London: Oxford University Press.

Hees, Peter. 2008. The Lives of Sri Aurobindo. New York: Columbia University Press.

\section{Submit your manuscript to a SpringerOpen ${ }^{\circ}$ journal and benefit from:}

- Convenient online submission

- Rigorous peer review

- Immediate publication on acceptance

- Open access: articles freely available online

- High visibility within the field

- Retaining the copyright to your article

Submit your next manuscript at $\boldsymbol{s p r i n g e r o p e n . c o m ~}$ 